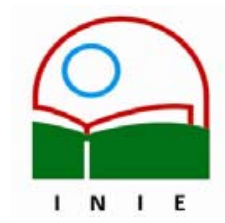

Universidad de Costa Rica

Facultad de Educación

Instituto de Investigación en Educación

ACTUALIDADES INVESTIGATIVAS EN EDUCACION

\title{
LA PERSPECTIVA DE LOS DOCENTES PRINCIPIANTES EN EDUCACION MEDIA SOBRE LA REFORMA EDUCATIVA EN URUGUAY
}

\author{
Opiniones, juicios y valoraciones sobre el funcionamiento de la \\ coordinación docente y el trabajo en proyectos de centro
}

\begin{abstract}
Eduardo Rodríguez Zidán ${ }^{1}$
Resumen: El objetivo de este artículo es presentar algunas conclusiones provisorias que surgen de una investigación cuyo propósito principal es conocer cómo valoran los profesores principiantes en educación media, dos elementos significativos de la reforma educativa en Uruguay: la coordinación docente y el trabajo en proyectos de centro. Luego de aplicar un cuestionario autoadministrado bajo supervisión del investigador a una muestra por conveniencia de 304 profesores que se desempeñan en 24 centros educativos; de los departamentos de Jump, Artigas, Paysandú y Río Negro, en la costa norte del país. Se incluyen egresados de dos modelos diferentes de formación docente y no titulados. El estudio concluye sobre las dificultades de promover los cambios educativos desde una lógica racional burocrática que no contempla los intereses reales del profesorado ni las prácticas tradicionales hegemónicas de las instituciones escolares.
\end{abstract}

PALABRAS CLAVES: REFORMA EDUCATIVA EN URUGUAY/ INNOVACIÓN/ PROFESORES PRINCIPIANTES/ COORDINACIÓN DOCENTE/ PROYECTO DE CENTRO/ EDUCACION MEDIA/

\begin{abstract}
The objective of this article is to present some provisional conclusions of the research of newly graduated middle school teachers' evaluation of two of the most representative innovations of the curricular reform of middle education in Uruguay: teacher coordination, and the work in institutional projects. The selected method was the application of a self-administered survey, supervised by a researcher, taking a convenient sample (not at random) of 304 professors which have less than 5 years of experience and carry out their labor in 24 schools in the departments of Jump, Artigas, Paysandú and Río Negro, located in the North coast of the country. Teachers graduated from two different models of teacher training and teachers who do not have a title are included. The study makes conclusions on the difficulties to promote the educative changes from a bureaucratic rational logic that does not contemplate the real interests of the teaching staff or the hegemonic traditional practices of the school institutions.
\end{abstract}

Key words: EDUCATIONAL REFORM IN URUGUAY/ INNOVATION/ NEWLY GRADUATE TEACHERS/ TEACHER COORDINATION/ OREVALL INSTITUTIONAL PROYECTI

\footnotetext{
1 Doctorando en Ciencias de la Educación por la Universidad de Málaga. España. Licenciado en Sociología por la Universidad de la República Oriental del Uruguay. Formador en Ciencias de la Educación. Profesor efectivo en Sociología de la Educación e Investigación Educativa Aplicada en el Cerp del Litoral, Uruguay.
}

Correo electrónico: cerzidan@yahoo.com.ar

Artículo recibido: 10 de agosto, 2005

Aprobado: 31 de octubre, 2005 


\section{Marco conceptual básico}

En las últimas dos décadas, es importante el conocimiento acumulado sobre el diseño, los objetivos alcanzados y el impacto cuantitativo de los procesos de reformas educativas en la región latinoamericana. Existe consenso en señalar qué, si bien se ha avanzado en términos de cobertura y aumento de la matrícula en la enseñanza básica obligatoria, todavía quedan muchos desafíos pendientes para lograr los objetivos de aprendizaje de calidad con equidad. (Aguerrondo 2001, Braslasky 2000, Mancebo 2002, Marchesi 2001, Unesco 1998, UnescoOrealc 1999, Cepal 1990, 1992, 1994, 1995, 1998, 1999; Gajardo 1999, Stiglitz 2003, Tedesco, 1996, 2002 Tenti, 2001).

En general, los especialistas en educación coinciden en destacar que los docentes deben asumir un nuevo rol profesional, demanda que es reconocida, además, por diferentes actores sociales, institucionales y corporativos. La sociedad y distintos grupos de presión, frecuentemente exigen y reclaman que los profesores sean cada vez más protagonistas no sólo de la formación académica de las nuevas generaciones sino de la contención de los principales problemas sociales de nuestra época que deben resolverse en el ámbito escolar.

En consecuencia, la presión social sobre los docentes es cada vez mayor y el nuevo contexto laboral docente debe ser objeto de análisis y reflexión. Las reformas educativas impulsadas en los últimos tiempos, tienden a jerarquizar el papel del profesorado como agente de cambio y en la mayoría de los casos proponen modificar los sistemas de formación docente reconociendo que la transformación del profesorado es condición de mejora de la calidad educativa.

Este es un fenómeno de alcance universal, que particularmente en América Latina tiene una política de expansión regional a partir de los años noventa. En ese contexto internacional, la reforma educativa en Uruguay se inicia recién en el año 1996 y la transformación del profesorado un año más tarde, mientras que los países del Mercosur y la región ya habían empezado, al inicio de la década, sus planes de innovación educativa reformulando el marco legal y aprobando, en sus respectivos parlamentos, nuevas leyes que regularan las nuevas políticas educativas. 


\subsection{La reforma educativa en educación media.}

En Uruguay, la reforma de la educación media, se discutió políticamente durante el año 1995, y empezó a implementarse al año siguiente, con el nuevo diseño curricular conocido como "Plan 96" (el 5/1/1996, fue aprobada por el Parlamento Nacional la Ley № 16.737 de Presupuesto Gastos e Inversiones de la Educación) Los cambios más significativos del nuevo programa se refieren al diseño curricular por áreas de conocimiento, la introducción de informática como área instrumental, nuevas formas de evaluación y de manera especial la apuesta a un nuevo esquema de gestión institucional de los centros, donde la coordinación entre profesores y la construcción de un proyecto institucional en cada establecimiento, representan dos de las innovaciones más importantes. Los estudios recientes en el campo de la educación, muestran que la reforma de la formación inicial de los profesores y el conocimiento de las condiciones de trabajo de los profesores en contextos de innovación y reforma educativa, ocupan cada vez más la atención de los investigadores.

En efecto, como señalan Mancebo y Vaillant (2002, p.1) tanto en los países desarrollados (Popewitz,1990) como en los países de la región de América Latina (Avalos, 1996; De Mello, 2002) en la últimos veinte años la formación de los docentes es un objeto de estudio permanente tanto para los especialistas como para los Estados nacionales que impulsan reformas educativas.

Las mismas autoras, analizan el caso uruguayo, revisando las diferentes modalidades de formación de profesores del sistema educativo nacional describiendo las distintas modalidades de la formación docente del profesorado de la educación media. En el artículo citado se señala la existencia de 3 modelos fundamentales en nuestro país (Mancebo y Vaillant, 2002, p. 3). En primer lugar se menciona al modelo IPA (Instituto de Profesores Artigas) con una propuesta fuertemente selectiva y exigente, cuyos cursos se dictan únicamente en la ciudad de Montevideo. En segundo lugar se destaca el modelo de los Institutos de Formación Docente, creado en 1977, que ofrece cursos en las ciudades del interior del país, con una modalidad de formación descentralizada del tipo de régimen semilibre (se cursan algunas asignaturas en el interior del país y otras deben ser examinadas en Montevideo). Y por último se destaca el modelo CERP (Centros Regionales de Profesores), establecimientos fundados por la reforma del año 1997, que se basó en un régimen de dedicación total (40 horas semanales) tanto para estudiantes como para docentes, cuyos 
objetivos fundamentales eran la profesionalización docente y la regionalización de los servicios para brindar oportunidades a todos los jóvenes que viven en el interior del país.

A los efectos de nuestro análisis, en esta investigación preferimos distinguir básicamente dos modelos de formación docente: uno que llamaremos IPA-IFD (el segundo es la aplicación del primero pero en el interior de nuestro país en los locales de los Institutos Normales) y el alternativo que se inicia con la reforma, denominado CERP (los Centros Regionales de Profesores ubicados en 5 departamentos del interior de la República) Esta última propuesta se diferencia de las primeras por contemplar un nuevo diseño curricular con un fuerte contenido en la formación en proyectos, la planificación educativa, el aprendizaje de informática aplicada y del inglés, la formación disciplinaria e interdisciplinaria, entre otros aspectos.

\subsection{Profesores principiantes en épocas de turbulencias y cambios educativos}

En este trabajo nuestro propósito es conocer de qué manera los profesores que ingresan a la docencia (sean titulados o no), enfrentan la difícil situación de ambientación en marcos institucionales ya establecidos, donde los nuevos docentes deben experimentar la transición de un "sujeto en formación" a "profesional autodirigido" (Imbernón, 1994). Este pasaje es particularmente complejo, en contextos de reforma educativa, porque implica que los docentes deben participar en escenarios donde se enfrentan viejos y nuevos modelos de formación docente y distintas culturas profesionales.

Esta etapa o momento de transición que experimentan los nuevos profesores en los inicios de su carrera ha sido profusamente estudiada, especialmente en Europa y los EEUU, no así en nuestro continente. Sobre este campo de investigación existe una extensa literatura especializada. En todos los casos hay acuerdos sobre la necesaria plasticidad y flexibilidad del desempeño de los profesores jóvenes en múltiples etapas, subetapas o fases con preocupaciones o características diferentes.

Por ejemplo, Vera (1988, p. 44) define claramente esta cuestión:

(..) parece lógico pensar que este período de tránsito se abre cuando, por primera vez se accede a la responsabilidad profesional en un centro de enseñanza, no es un período uniforme ni idéntico en todas sus fases, sino que por el contrario, en su transcurso se producen experiencias y aprendizajes que completan el bagaje 
pedagógico anteriormente adquirido, afectando la personalidad del debutante y la manera en que este percibe y sume su nuevo rol de profesor "(...)el profesor principiante es una persona, generalmente joven, que se encuentra en un momento de transición entre los conocimientos, habilidades, destrezas y actitudes aprendidas a lo largo de tres años de estudios teórico-prácticos, y la puesta en acción de lo aprendido en el marco real de la intervención pedagógica

Parece interesante, además, examinar este momento como una posibilidad para evaluar, como plantea Vera (1989, p.17); la pertinencia de los planes de formación inicial, investigar en sentido prospectivo las políticas de formación docente a seguir, prevenir las situaciones de malestar docente y diseñar "modalidades de formación continua centradas en las escuelas.

Algunos trabajos recientes en América Latina, proponen, desde una visión comprehensiva, la necesidad de identificar en los profesores debutantes, 3 ámbitos de reflexión que se presentan en forma dinámica e interactiva: los personales, los formativos y los relativos a la práctica profesional (Cornejo, 1999). Por otra parte, Imbernón (1994) desde un análisis complementario, identifica 3 etapas en ese proceso de inserción profesional: la básica, la de inducción profesional y la de perfeccionamiento.

Analizando la propuesta de Vonk, Vera (1988, p. 55) pone énfasis en las categorías de micro y macro nivel, asociadas a los dos períodos fundamentales del primer año de la experiencia docente: la etapa de "umbral" y de "maduración". Otros autores, en cambio, hablan de ciclos en la vida de las profesiones, utilizando el concepto de trayectoria profesional, considerando la variable experiencia docente como criterio de clasificación. Desde esta última perspectiva, la propuesta de Huberman, es analizada por Bolívar (1999, p. 59) que se interesa en destacar las principales fases de los profesores de Secundaria, utilizando como variable de discriminación los años de experiencia docente. Con este criterio, el autor identifica 5 momentos: fase 1: exploración (0-3 años), fase 2: estabilización (4-6 años), fase 3: experimentación (7-18 años), fase 4: serenidad/ distanciamiento afectivo. (1930 años) y fase 5: Conservadurismo y queja. (31 y 40 años de experiencia docente).

Según la contribución de este autor, habría una "secuencia más o menos normativa en el ciclo de vida profesional de los docentes, con sus propias transiciones o crisis, de cuya 
resolución dependerá el curso posterior. En cualquier caso - como resalta reiteradamente Huberman- no se puede prever linealmente las fases de cada profesor" (Bolívar, 1999, p. 61)

Evidentemente, existe una fuerte asociación entre las condiciones de ingreso al trabajo docente, es decir el desempeño de los nuevos profesores jóvenes que ingresan al campo laboral, su preparación inicial, la construcción previa de lo que significa para ellos ser "un buen profesor" y la realidad de la vida cotidiana de cualquier centro escolar de Educación Media.

En el vasto campo de investigación que reseñamos más arriba, surge la necesidad de investigar los problemas de los profesores debutantes y plantearse el objetivo de conocer la relación entre los modelos de formación inicial de docentes y el choque que se produce al llegar a las instituciones escolares. Este choque adquiere particular intensidad si los docentes tienen que ser impulsores de las innovaciones que toda reforma educativa decide introducir en la enseñanza.

El profesor J.M. Esteve (1996, p. 66) retomando a Veerman, señala con claridad el conflicto que los profesores experimentan en sus primeros años de trabajo:

En el primer año de trabajo en la enseñanza los profesores sufren su primera crisis de identidad profesional, al descubrir la falta de congruencia entre la realidad de la enseñanza y la imagen que cada uno se había forjado de ella durante su periodo de formación inicial. Así, van a necesitar modificar su conducta, sus actitudes, e incluso sus opiniones sobre la enseñanza.

El marco conceptual que hemos sintetizado más arriba, es una guía para orientar nuestro trabajo exploratorio, con la finalidad de comprender cómo es la inserción de los profesores principiantes de educación media en Uruguay, a partir del análisis de dos innovaciones centrales de la reforma educativa : la coordinación docente y el trabajo en proyectos de centro.

\section{Universo de análisis y Metodología}

Nuestro universo de investigación está conformado por un total de 272 docentes principiantes de educación media de la región litoral del Uruguay, seleccionados mediante una muestra estratégica de un total de 540 docentes que tienen 5 o menos años de 
experiencia. Los profesores se desempeñan en 24 centros de educación media (8 de Salto, el mismo número de Paysandú, 5 de Artigas y 4 de Río Negro). El listado original de profesores se creó mediante entrevista telefónica con las autoridades de cada liceo o escuela técnica. El método aplicado fue el registro por cuestionario, en el propio lugar de trabajo, mediante la utilización de una encuesta autoadministrada bajo supervisión del investigador. En la mayoría de los casos se viajó a cada centro educativo para supervisar las tareas de campo. En ocasiones, por dificultades de traslado, se enviaron los formularios vía postal. En este artículo se analizan solamente las preguntas relacionadas con el objetivo de este trabajo ${ }^{2}$.

En general son preguntas con respuestas cerradas, o de cafetería, pero también se incluye el estudio de las representaciones docentes mediante preguntas abiertas. El estudio se efectuó entre los meses de agosto y diciembre del año 2004.

\subsection{Análisis de resultados}

El propósito de mejorar las capacidades para el trabajo docente en equipo, el intercambio de experiencias entre profesores y la necesidad de coordinar estrategias pedagógicas que potencien la calidad de la enseñanza media, no son propuestas exclusivas de la reforma iniciada a partir del año 1996. Por ejemplo, en las innovaciones introducidas por las autoridades del período 1991-1995, se planteaba la necesidad de "remunerar horas docentes de coordinación" para implementar el curriculo por áreas anunciado en la propuesta del primer período del año 1986" (ANEP, 1996, p. 13). El nuevo plan de secundaria 1996, establece como una de las orientaciones metodológicas principales, la tarea de coordinación de los profesores, para "planificar, desarrollar el curriculum y las propuestas pedagógicas con sus pares y el equipo de dirección" (ANEP, 1996, p. 15).

La idea original implantada en el programa del Plan 1996, suponía la contratación de profesores con el régimen de "paquete horario" de 30 horas semanales, por dos motivos fundamentales. Por un lado, aseguraba el vínculo institucional del profesor con un centro educativo donde debe participar activamente, evitando con ello el desplazamiento constante de un centro de estudio a otro, la complejidad de enfrentar diferentes realidades

\footnotetext{
${ }^{2}$ El estudio es parte de una tesis de doctorado en curso, -Facultad de Ciencias de la Educación- Universidad de Málaga, bajo responsabilidad del autor de este artículo. El formulario de la encuesta contiene 254 variables de investigación, de las cuáles se seleccionaron algunas de las referidas al tópico central de este informe.
} 
institucionales así como el multiempleo simultáneo. Por otra parte, la modalidad del contrato implicaba que las tareas de aula representaban 25 horas semanales de compromiso, destinando las 5 horas restantes para desempeñar labores de coordinación con sus pares y con la dirección, planificación pedagógica, investigación, etc.

Lamentablemente, la fragmentación del diseño curricular en unidades menores a las 30 horas, dificultades administrativas y de gestión de los centros, impidieron a la mayoría de los profesores que fueran contratados por paquetes horarios en uno o dos lugares de trabajo, lo que llevó a que continuaran eligiendo horas y grupos en distintos planes, programas, zonas y hasta departamentos diferentes ${ }^{3}$.

De esta manera, existen serias dificultades para coordinar las tareas docentes, por la dinámica del cambio permanente de establecimiento educativo (cada uno con su propia lógica de funcionamiento), el hecho de trabajar con varios diseños curriculares a la vez y atender un número elevado de alumnos que vienen de diferentes contextos sociales, cognitivos y culturales. No obstante, -como ya lo hemos desarrollado en capítulos anterioreslos cambios promovidos a partir del año 1996, implicaron transformaciones en el campo curricular (un nuevo agrupamiento de asignaturas por áreas, nuevas áreas instrumentales, etc) y particularmente modificaciones relevantes en la gestión de los centros de enseñanza En este último aspecto, las horas de coordinación así como el diseño de proyectos educativos institucionales son las propuestas que más fuertemente impactaron en la enseñanza media.

Sobran razones para justificar, entonces, la importancia de conocer las valoraciones de estas nuevas propuestas, en este caso, según la opinión de los profesores principiantes.

\subsubsection{La Coordinación docente}

Si entendemos por coordinación en la enseñanza la necesidad de intercambiar experiencias, enfoques o programas entre aquellos docentes que comparten el mismo grupo de alumnos y la misma institución, esta actividad ha sido, y continúa siendo, un aspecto central del perfil profesional de los docentes. Con seguridad, los profesores- por lo menos en la historia reciente del siglo pasado- siempre se han visto obligados a intercambiar experiencias, 
coparticipar en proyectos o discutir con sus pares sobre la metodología de la enseñanza, los programas o diferentes estrategias didácticas. Lo nuevo, a partir de las reformas educativas de los 90 , es que se ha legislado sobre el tema, llegando al extremo de que en nuestros días, las tareas de coordinación docente (de aula o de gestión institucional) son legitimadas y hasta retribuidas por la administración.

Para analizar esta cuestión, según las valoraciones de los profesores jóvenes consultados, nos planteamos las siguientes preguntas: ¿con quienes coordinan los profesores debutantes? ¿cuándo lo hacen y con que frecuencia? ¿cuáles son los temas que predominan en las reuniones de coordinación? ¿qué opinan del funcionamiento de la coordinación? ¿quién define la agenda de discusión? ¿cómo es la comunicación entre los docentes? ¿cómo es la coordinación entre profesores que tienen distintos niveles de formación?

La coordinación docente, se puede expresar en dos ámbitos institucionales, en el sentido más restringido los profesores coordinan aspectos curriculares o pedagógicos relativos a sus disciplinas o áreas de conocimientos donde se desempeñan (por ejemplo: coordinación entre profesores del área de ciencias sociales). En un sentido más amplio, los docentes coordinan todas las actividades (no sólo las relacionadas con estrategias de aula) con sus pares y con la dirección, en instancias democráticas convocadas por la dirección escolar denominadas "coordinación del centro".

Este es el aspecto más novedoso de la reforma del Plan 96, ya que abre un espacio para el debate y la participación docente a través de un proceso constituyente de carácter democrático en las instituciones de enseñanza media ${ }^{4}$.

\footnotetext{
${ }^{3}$ Por ejemplo, en uno de los centros relevados en esta investigación se constató que casi el $50 \%$ del profesorado viajaba $180 \mathrm{Km}$. (ida y vuelta) para participar, únicamente, de las reuniones de coordinación.

${ }^{4}$ De acuerdo con las disposiciones reglamentarias vigentes, un cargo de 9 horas docentes tiene 1 hora más de coordinación; un cargo entre 10 y 20 horas docentes tiene 3 horas de coordinación. Los cargos con más de 20 horas tienen 4 horas de coordinación. De las 5 horas de coordinación que tiene el"paquete" de 30 horas docentes, los Directores, normalmente destinan 2 horas para la coordinación de centro y 3 horas para la coordinación por nivel. Los profesores con pocas horas, sólo coordinan a nivel del centro. Recordemos que por imposibilidad administrativa, el acceso a paquetes horarios en un mismo centro es sólo para una minoría de docentes, generalmente los efectivos de mayor antigüedad. La mayoría completa su carga horaria eligiendo diferentes grupos en dos o tres establecimientos.
} 
Ahora bien: ¿con quiénes se sienten más cómodos los profesores jóvenes para coordinar sus actividades de enseñanza? Leyendo los datos que se muestran en la siguiente Tabla, podemos descubrir algunas conclusiones interesantes.

\section{Tabla $\mathbf{N}^{\circ} 1$}

La coordinación docente: ; a quiénes prefieren los profesores debutantes?

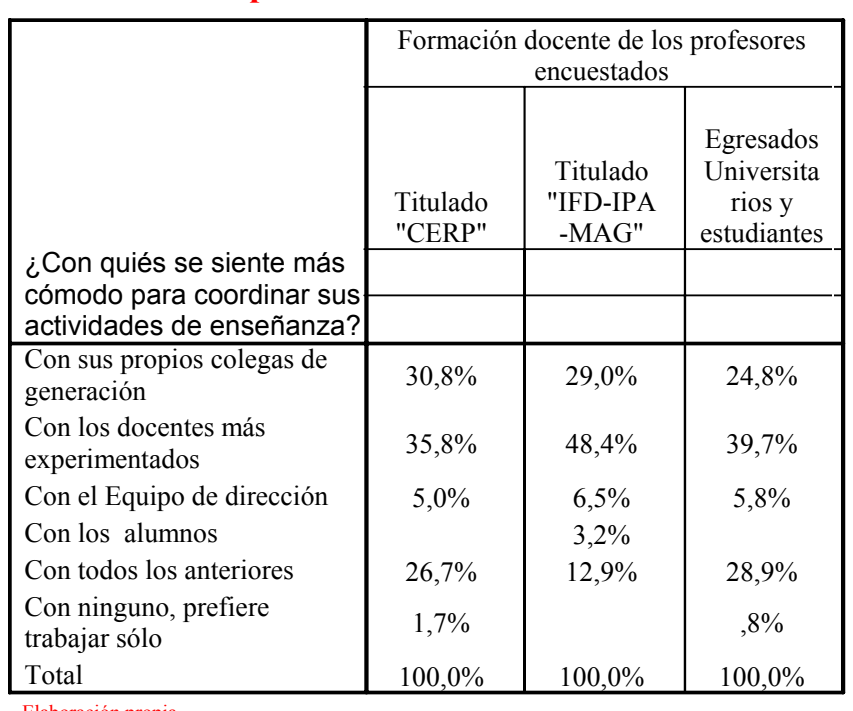

Según las respuestas de los profesores consultados podemos confirmar lo siguiente: a) en primer lugar las preferencias indican que los profesores se sienten cómodos trabajando entre sus pares, llamando la atención el escaso número de profesores que coordina tareas con el equipo de dirección escolar de su centro respectivo, b) en segundo orden, un número importante de profesores debutantes recurre a sus colegas más experimentados, en el caso de los egresados del CERP es el 35,8\%, porcentaje que aumenta al 39,7\% entre los docentes sin título y a $48,4 \%$ entre los profesores egresados el IPA-IFD, c) el resto de los profesores (entre el 25 y el $30 \%$ en cada nivel de formación) coordina con sus propios compañeros de generación. Probablemente, esto último indique ciertas dificultades para insertarse en la dinámica institucional de cada centro, o tal vez la tendencia a sentirse identificado con determinado modelo de formación docente.

¿En que momento coordinan los profesores de la enseñanza media? La inserción institucional de los profesores jóvenes no es distinta a cualquier profesor promedio de la educación media: debe atender, a la vez, muchos grupos de alumnos, con distintos 
programas y en diferentes centros que tienen lógicas de funcionamiento, horarios y dinámicas muy heterogéneas. Por esos motivos, no es fácil para el sistema educativo crear un espacio de coordinación que no interfiera en los horarios de clase que los docentes tienen en otras instituciones de enseñanza. Por esa razón preguntamos si los horarios de coordinación (el día y la hora es determinada por la dirección de cada establecimiento de forma autónoma) facilitaba o dificultaba las reuniones de coordinación.

\section{Tabla $\mathbf{N}^{\circ} 2$}

Opinión de los docentes sobre el horario de las reuniones de coordinación

\begin{tabular}{|c|c|c|c|c|}
\hline \multirow{3}{*}{$\begin{array}{l}\text { En este centro, las } \\
\text { reuniones de } \\
\text { coordinación se llevan a } \\
\text { cabo en un horario que } \\
\text { facilita su asistencia? }\end{array}$} & \multicolumn{4}{|c|}{ SUBSISTEMA DONDE TRABAJA } \\
\hline & \multicolumn{2}{|c|}{ Secundaria } & \multicolumn{2}{|c|}{ Educación Técnica(U TU) } \\
\hline & Casos & $\%$ & Casos & $\%$ \\
\hline si & 130 & $84,4 \%$ & 89 & $75,4 \%$ \\
\hline no & 24 & $15,6 \%$ & 29 & $24,6 \%$ \\
\hline Total & 154 & $100,0 \%$ & 118 & $100,0 \%$ \\
\hline
\end{tabular}

Elabroación propia

Tal como se observa en la Tabla $N^{\circ} 2$, existe una proporción importante de profesores, especialmente los que tienen mayor carga horaria en la educación técnica-, que están desconformes con el horario de la coordinación. En efecto, el 15,6 \% del profesorado de educación secundaria y uno de cada cuatro $(24,6 \%)$ profesores de la enseñanza técnica, tienen dificultades para participar de las reuniones de coordinación, porque el día y la hora propuesta por la dirección escolar seguramente coinciden con otras actividades, o bien por las complicaciones propias del multiempleo docente. No es un dato menor, podría demostrarse con éstos y otros ejemplos que la realidad escolar echa a tierra muchas de las innovaciones pensadas desde el mundo abstracto de los investigadores y planificadores de la enseñanza. Uno de los motivos que justifican la coordinación docente a nivel del centro es la construcción de una gestión democrática y participativa donde todos los agentes educativos comparten un proyecto en común. Por esa razón es relevante saber quiénes definen la agenda de discusión, que temas se discuten en los proyectos de centro así como la evaluación primaria que los propios docentes principiantes realizan de sus primeras experiencias en la coordinación de actividades. 
También es una forma indirecta de conocer el grado de autonomía del profesorado, el carácter democrático de la participación social así como el control por parte de las autoridades en la dirección y definición de los temas que se discuten en las reuniones de centro.

La información estadística que se exhibe en la Tabla $N^{\circ} 3$, indica con claridad que son los directores quiénes definen, en primer lugar, los asuntos a discutir en las horas de coordinación (con una mayor proporción de los directivos de secundaria $(54,9 \%)$ que en la educación técnica $(47,6 \%)$. En segundo lugar, uno de cada cuatro profesores principiantes opina que la agenda se coordina entre la dirección y los docentes, con más fuerza en la educación técnica (32\%) que en secundaria $(20,4 \%)$

\section{Tabla No 3}

'aracterísticas de las reuniones de coordinación docente: ¿quiéı define la agenda para la discusión?

\begin{tabular}{|l|c|c|c|c|}
\hline \multirow{2}{*}{} & \multicolumn{4}{|c|}{$\begin{array}{c}\text { SUBSISTEMA DONDE } \\
\text { TRABAJA }\end{array}$} \\
\cline { 2 - 5 } & \multicolumn{3}{|c|}{$\begin{array}{c}\text { Educación } \\
\text { Técnica (UTU) }\end{array}$} \\
\cline { 2 - 5 } & \multicolumn{2}{|c|}{ Secundaria } & & \\
\cline { 2 - 5 } ¿Quién define la agenda de discusión? & $\mathrm{N}$ & $\%$ & $\mathrm{~N}$ & $\%$ \\
\cline { 2 - 5 } & 12 & 8,5 & 4 & 3,9 \\
Los docentes de forma autónoma & 78 & 54,9 & 49 & 47,6 \\
Los docentes a propuesta de la dirección & 20 & 14,1 & 14 & 13,6 \\
Coordinación entre docentes y equipo de & 29 & 20,4 & 33 & 32,0 \\
dirección & 3 & 2,1 & 3 & 2,9 \\
La comunidad educativa en general & 142 & 100,0 & 103 & 100,0 \\
Total &
\end{tabular}

Elabroación propia

Por último, solamente el $8,5 \%$ del profesorado de secundaria y apenas el 3,9\% de sus pares de la enseñanza técnica, opinan que los docentes, de forma autónoma, tiene espacios para proponer los temas a discutir en las reuniones de coordinación docente. ¿Qué cuestiones se discuten? ¿Cuáles son las prioridades de las autoridades en cada centro según la opinión docente? 


\section{Tabla $\mathbf{N}^{\circ} 4$}

\section{¿Qué se discute en las reuniones de coordinación} docente?

\begin{tabular}{|l|c|}
\hline & Indicador \\
\cline { 2 - 2 } Temas de la Coordinación docente & $\%$ \\
\hline Proyectos institucionales & 16,1 \\
Problemas del alumno & 54,0 \\
CAlidad de la enseñanza & 13,7 \\
Información institucional de & 13,7 \\
2do.orden & 2,4 \\
Valores & 100,0 \\
Total & \\
\hline
\end{tabular}

A primera vista no parece fácil distinguir cuáles podrían ser los temas que se tratan en las reuniones de coordinación de cada centro educativo, generalmente integradas por varias decenas de profesores (en muchos casos hay más de 100 docentes en una misma reunión). Darle voz al profesorado, tal como propone José Contreras en un excelente artículo sobre el sentido educativo de la investigación (1991, p. 5), es un objetivo que pocas instituciones se proponen, generalmente porque prefieren gestionar los cambios respetando la tradición jerárquica de las viejas instituciones estatales. Por esos motivos, al consultar a los docentes sobre su participación en la toma de decisiones en el centro y en el debate sobre qué se debe discutir en un proyecto de coordinación, nos encontramos con opiniones que reflejan distintas sensaciones, experiencias y percepciones.

Un sector del profesorado joven manifestó que en las reuniones de coordinación se "pierde el tiempo" porque se tratan temas donde "se culpabiliza al profesorado del fracaso educativo", "se culpa al docente de no tener la libreta al día" o bien, se da lectura al marco normativo vigente y a las comunicaciones oficiales que bajan desde las autoridades centrales de la administración. No fueron pocos los profesores que manifestaron su desacuerdo con la falta de una agenda de discusión que definiera prioridades, ya que se trataban cuestiones tan variopintas como la concurrencia a los actos oficiales, la pérdida de llaves, información administrativa o, como lo dijeron algunos docentes del departamento de Salto "no se trata ningún tema, simplemente es un lugar para el chusmerío y el divague". A este conjunto de temáticas las hemos definido como "Información institucional de 2do. orden" porque no jerarquizan el debate pedagógico didáctico, ni el diseño de un proyecto 
institucional definido tal como lo recomiendan las nuevas orientaciones para mejorar la gestión de los centros.

El trabajo en la elaboración, seguimiento y evaluación de un proyecto institucional es otro de los temas señalados por los profesores, denominamos a esta categoría como "Proyecto de centro". Al procesar la información nos encontramos que en muchos lugares se debate sobre las condiciones socioculturales de los alumnos, la repetición, deserción, rezago, la disciplina, etc, características que hemos nombrado como "Problemática del alumno".

Además, descubrimos que para otros docentes la prioridad está en conocer los problemas de las prácticas de la enseñanza, la formación docente y las cuestiones didáctico pedagógicas. A esta categoría la rotulamos como "Calidad de la enseñanza".

Por último, observamos que algunos centros priorizan la discusión sobre la formación en valores, la motivación de alumnos y profesores para educar a las nuevas generaciones de adolescentes. Denominamos a estos temas como "Valores". De esta manera, tal como se expone en la Tabla $N^{\circ} 4$, elaboramos 5 agrupamientos que reflejan el debate y las prioridades establecidas -en la mayoría de los casos por los directores- para tratar en la Sala de Coordinación con el objetivo de mejorar la gestión institucional.

En primer lugar, comprobamos que de todos los problemas considerados, hay una primacía e interés por discutir sobre "la problemática del alumno" (54\%), especialmente las dificultades que implica la heterogeneidad del alumnado y sus consecuencias más visibles como las altas tasas de repetición y abandono, el rezago, el bajo rendimiento, la cuestión del orden, disciplinamiento, diferentes niveles de aprendizaje, etc.

En segundo orden de prioridades, surgen tres agrupamientos temáticos: el vinculado con los proyectos institucionales (16\%), la calidad de la enseñanza $(13,7 \%)$ y el tratamiento de temas institucionales de 2 do. orden $(13,7 \%)$. La formación en valores no parece ser un tema jerarquizado por las reuniones de coordinación, o por el contrario, tal vez sí lo es pero los docentes incluyen estos temas en la categoría "problemas del alumno".

En síntesis, las preocupaciones presentes en las reuniones de coordinación de los 24 establecimientos examinados, consideran a la "problemática del "alumno" como eje central. 
Las cuestiones relativas a la calidad de la enseñanza y al diseño del proyecto educativo de centro son prioridad para una de cada siete instituciones de enseñanza media. Llama la atención que el $13 \%$ de las opiniones docentes confirma que en muchos centros las horas de coordinación no reflejan un espacio de discusión académica sino que por el contrario se utiliza el tiempo para transmitir información administrativa o tratar temas relativos al control burocrático de la tarea docente. ¿Existen diferencias según el subsistema?

Los datos que se muestran a continuación son elocuentes al respecto. Los proyectos institucionales y la calidad de la enseñanza se discuten con mayor frecuencia en educación secundaria que en la enseñanza técnica. Por el contrario, en ésta predominan las preocupaciones referidas a problemas del alumnado y las de carácter institucional de 2do. orden. Es muy probable que esto sea así como consecuencia de dos factores. Por un lado la mayor proporción de docentes titulados en educación media está relacionada con la discusión pedagógica y la formulación de proyectos de centro. Por otro, es posible que los directores de las instituciones de enseñanza técnica carezcan de formación para la gestión académica de los centros, y en consecuencia procedan, en muchos casos, a sobrecargar las horas de coordinación con tareas administrativas o de simple información burocrática. Es una hipótesis tentativa que requiere mayor profundización.

\section{Tabla $\mathbf{N}^{\circ} 5$}

Distribución de los temas que de discuten en las salas de coordinación, según el subsistema

\begin{tabular}{|l|c|c|}
\hline \multirow{2}{*}{} & \multicolumn{2}{|c|}{ SUBSISTEMA } \\
\cline { 2 - 3 } & Secundaria & Educación Técnica \\
\cline { 2 - 3 } Agenda de discusión & Temas & Temas \\
\cline { 2 - 3 } Proyectos institucionales & $20,6 \%$ & $\%$ \\
Problemas del alumno & $50,0 \%$ & $9,4 \%$ \\
CAlidad de la enseñanza & $15,1 \%$ & $60,0 \%$ \\
Información institucional & $10,3 \%$ & $11,8 \%$ \\
de 2do.orden & $4,0 \%$ & $18,8 \%$ \\
Valores & $100,0 \%$ & \\
Total & \multicolumn{2}{|}{} \\
\hline
\end{tabular}

Es interesante conocer, para continuar investigando sobre las opiniones del profesorado debutante sobre esta innovación, cómo valoran el funcionamiento de la Sala de Coordinación. Con ese fin, preguntamos a los docentes si consideraban que la coordinación docente funciona muy bien, bien, regular o mal. Las respuestas, exhibidas en la Tabla $N^{\circ} 6$ 
indican que en general la opinión del profesorado están divididas. La mitad tiene una imagen positiva (el 50,6 \% afirma que funciona bien o muy bien) pero el resto del profesorado es muy crítico al respecto (31,1\% afirma que funciona regular y el $18,3 \%$ dice que funciona mal).

\section{Tabla $\mathbf{N}^{\circ} 6$}

)pinión de los docentes sobre el funcionamientc de la coordinación

\begin{tabular}{|c|c|c|}
\hline \multirow{2}{*}{} & \multicolumn{2}{|c|}{$\begin{array}{c}\text { nn su opinión: ¿cómo ha funcionado le } \\
\text { coordinación? }\end{array}$} \\
\cline { 2 - 3 } & $\mathrm{N}$ & $\%$ \\
\hline Muy bien & 35 & $13,6 \%$ \\
Bien & 95 & $37,0 \%$ \\
Regular & 80 & $31,1 \%$ \\
Mal & 47 & $18,3 \%$ \\
Total & 257 & $100,0 \%$ \\
\hline
\end{tabular}

¿Estas opiniones cambian según la formación docente o el nivel de la enseñanza media donde se ocupan los docentes? Para contestar esta pregunta, vamos a interpretar los siguientes datos.

En términos generales las opiniones sobre el funcionamiento de la coordinación, no parecen ser diferentes si comparamos la experiencia en cada subsistema (en promedio la mitad tiene opinión positiva y el resto tiene críticas al respecto) pero con algunos matices en las diferencias según el porcentaje en cada categoría. Puede notarse que las respuestas más críticas del tipo "funciona mal" son algo superiores en la enseñanza técnica $(21,8 \%)$ que en secundaria $(15,6 \%)$.

¿Cambia la opinión según el Departamento donde trabajan los docentes principiantes? Los datos se muestran en la Tabla № 8. 


\section{Tabla $\mathbf{N}^{\circ} 7$}

Opinión del profesorado debutante sobre la coordinación según subsistema

\begin{tabular}{|l|c|c|c|c|}
\hline \multirow{2}{*}{$\begin{array}{l}\text { En su opinión: } \\
\text { ¿cómo ha } \\
\text { funcionado la } \\
\text { coordinación? }\end{array}$} & \multicolumn{4}{|c|}{$\begin{array}{c}\text { SUBSISTEMA DONDE } \\
\text { TRABAJA }\end{array}$} \\
\cline { 2 - 5 } & \multicolumn{3}{|c|}{ Secundaria } & \multicolumn{2}{c|}{$\begin{array}{c}\text { Educación } \\
\text { Técnica (UTU) }\end{array}$} \\
\cline { 2 - 5 } Muy bien & $\mathrm{N}$ & $\%$ & $\mathrm{~N}$ & $\%$ \\
Bien & 19 & $12,9 \%$ & 16 & $14,5 \%$ \\
Regular & 55 & $37,4 \%$ & 40 & $36,4 \%$ \\
Mal & 50 & $34,0 \%$ & 30 & $27,3 \%$ \\
Total & 23 & $15,6 \%$ & 24 & $21,8 \%$ \\
\hline
\end{tabular}

\section{Tabla No 8}

Opinión sobre el funcionamiento de la Coordinación, según el departamento donde trabajan los profesores

\begin{tabular}{|c|c|c|c|c|c|c|c|c|}
\hline & \multicolumn{8}{|c|}{ Departamento } \\
\hline & \multicolumn{2}{|c|}{ Artigas } & \multicolumn{2}{|c|}{ Salto } & \multicolumn{2}{|c|}{ Paysandú } & \multicolumn{2}{|c|}{ Río Negro } \\
\hline & Casos & $\%$ & Casos & $\%$ & Casos & $\%$ & Casos & $\%$ \\
\hline Muy bien & 9 & $19,6 \%$ & 7 & $5,8 \%$ & 13 & $21,0 \%$ & 6 & $20,7 \%$ \\
\hline Bien & 20 & $43,5 \%$ & 31 & $25,8 \%$ & 29 & $46,8 \%$ & 15 & $51,7 \%$ \\
\hline Regular & 12 & $26,1 \%$ & 43 & $35,8 \%$ & 17 & $27,4 \%$ & 8 & $27,6 \%$ \\
\hline Mal & 5 & $10,9 \%$ & 39 & $32,5 \%$ & 3 & $4,8 \%$ & & \\
\hline Total & 46 & $100,0 \%$ & 120 & $100,0 \%$ & 62 & $100,0 \%$ & 29 & $100,0 \%$ \\
\hline
\end{tabular}

De la lectura de la Tabla $N^{0} 8$, se puede concluir que la proporción de docentes que manifiestan reparos sobre las actividades de coordinación, es diferente según la región donde trabajan (4). Las críticas más importantes aparecen en Salto (32,5\% dice que funciona mal la coordinación) que en el resto. Debe tenerse en cuenta, para interpretar correctamente la situación, que todas las encuestas registradas en el departamento de Salto y Paysandú fueron supervisadas, aplicadas y levantadas directamente por el investigador, no así en los casos de Río Negro y Artigas (enviadas y devueltas por el servicio postal). Es probable, entonces, que la calidad de los datos referidos a las preguntas abiertas que intentan evaluar una innovación cuya principal responsabilidad recae en la dirección escolar, sea puesta en duda en ciertos casos, sobre todo en aquellas situaciones donde algunos directores 
permanecieron presentes en el momento que sus profesores completaran el formulario, 0 bien, si no estaban presentes, daban instrucciones "para que entregaran los formularios en la Dirección". No obstante, el malestar general del profesorado sobre la forma en que se llevan a cabo las coordinaciones es evidente. Tiene sentido, pues, preguntarse lo siguiente:

¿Cuáles son las principales razones y argumentos del profesorado para valorar como positiva o negativa la experiencia del trabajo en coordinación? Para continuar profundizando sobre este asunto, le pedimos a los docentes encuestados que expresaran sus valoraciones, desde una perspectiva interpretativa, respondiendo a una pregunta abierta que fue la siguiente. ¿Por qué razón cree Ud. que la coordinación funciona...muy bien..bien.. regular... o mal....?.

El procedimiento aplicado fue el de registrar e interpretar las cuatro clases de juicios (dos positivos: "funciona muy bien" y "funciona bien"; dos negativos: "funciona regular" y "funciona mal") agrupando las valoraciones en cada una de las categorías señaladas. En la Tabla $\mathrm{N}^{\circ} 9$, se sintetizan los principales juicios positivos y negativos del profesado.

\section{Tabla $N^{\circ} 9$}

Diferentes tipos de Juicios sobre la Coordinación

\begin{tabular}{|c|c|}
\hline \multicolumn{2}{|c|}{ JUICIOS POSITIVOS SOBRE LA COORDINACIÓN } \\
\hline Funciona "muy bien" & Funciona "bien" \\
\hline $\begin{array}{l}\text { "Se logran acuerdos y se coordinan } \\
\text { actividades porque la dirección tiene muy } \\
\text { claras cuales son sus objetivos" } \\
\text { "Porque confían en nuestro trabajo y eso } \\
\text { nos permite seguir adelante innovando } \\
\text { según los casos que nos presenten." "Se } \\
\text { lograron acuerdos, se establecieron } \\
\text { estrategias y formularon proyectos se } \\
\text { están implementando. Se trabajo sobre } \\
\text { temas de interés de los docentes, se } \\
\text { trabajo con autoformación" "Porque es un } \\
\text { espacio en el cual trabajamos en equipo, }\end{array}$ & $\begin{array}{l}\text { "A veces es muy buena porque depende del tema a } \\
\text { desarrollar y el interés que este despierte, otras } \\
\text { veces sólo se va para cumplir el horario; se habla.., } \\
\text { etc." "“'Son temas que importan a todos" "En muchas } \\
\text { oportunidades se han logrado buenos resultados } \\
\text { pero la mayoría de las veces la coordinación es para } \\
\text { darnos comunicados" "“'Se han trabajado temas } \\
\text { específicos del centro, sobre los alumnos y se han } \\
\text { realizado talleres" "Porque tratamos temas de interés } \\
\text { general sobre todo en cuanto a la formación de } \\
\text { docentes en cuanto a los aprendizajes de los } \\
\text { alumnos" "“Porque siempre se plantearon temas de }\end{array}$ \\
\hline
\end{tabular}


se discute, se aporta, se reflexiona, interés y trataron de resolverse." "Porque tenemos comparte.. los problemas entre todos los un tema definido para trabajar en cada docentes y la dirección" coordinación." " "Porque se han logrado los " Porque los objetivos propuestos hasta el objetivos planteados" "“El clima de trabajo del momento se han llevado a cabo" "Permite equipo docente es bueno" "Porque realmente hemos informarnos de los procesos, dificultades logrado alcanzar algunos objetivos propuestos" " A y aspectos positivos entre docentes, veces el tiempo no alcanza y quedan cosas para sobre temas áulicos e institucionales. atrás" "La mayoría de los docentes no todos tienen Permite actividades que benefician la una buena disposición y voluntad para trabajar" "Me institución y los alumnos." ha tocado coordinar con docentes que no pertenecen a mi grupo" "Trabajar en diferentes "Todos tenemos interés en los temas horarios de coordinación (Coord. Por nivel" planteados"

"Se obtienen buenos resultados, buena comunicación institucional y compromiso con actividades" " Se respetan las opiniones y se llegan a decisiones consensuadas"

JUICIOS NEGATIVOS SOBRE LA COORDINACIÓN

\begin{tabular}{|c|c|}
\hline & \\
\hline $\begin{array}{l}\text { "Porque no se trabajan temas de importancia } \\
\text { como ejemplo "perfeccionamiento docente (no } \\
\text { se da lugar...)" " Falta de interés del equipo } \\
\text { docente" } \\
\text { "Debe existir mayor participación docente en } \\
\text { la planificación" "Porque podrían tratar otros } \\
\text { temas como por ejemplo proyectos de aula, } \\
\text { evaluación, etc" " Por los temas } \\
\text { tratados" "A veces hay temas obvios que no } \\
\text { necesitan ser discutidos" "Los profesores no } \\
\text { se comprometen en la coordinación" "Falta de } \\
\text { participación y compromiso" "Falta de pautas } \\
\text { para instrumentar la coordinación" "Por falta }\end{array}$ & $\begin{array}{l}\text { "Cansancio de los docentes y poca valoración } \\
\text { del espacio logrado debido a imposiciones de } \\
\text { las autoridades" " No existe la participación } \\
\text { docente, "todo lo que diga el docente será } \\
\text { utilizado en su contra" "Parece que no tenemos } \\
\text { objetivos claros, muchas veces, es sólo pasar } \\
\text { el tiempo, no se aprovecha.." "Tiene poca } \\
\text { aplicación práctica. Se hace mucho hincapié en } \\
\text { el pasaje de grado universal, la no deserción, } \\
\text { hay presión de autoridades, indirectamente } \\
\text { sobre el docente para promover alumnos" " Por } \\
\text { no poder coordinar con los colegas del mismo } \\
\text { paquete..." } \\
\text { "Falta de comunicación, diálogo efectivo entre }\end{array}$ \\
\hline
\end{tabular}




\begin{tabular}{|c|c|}
\hline 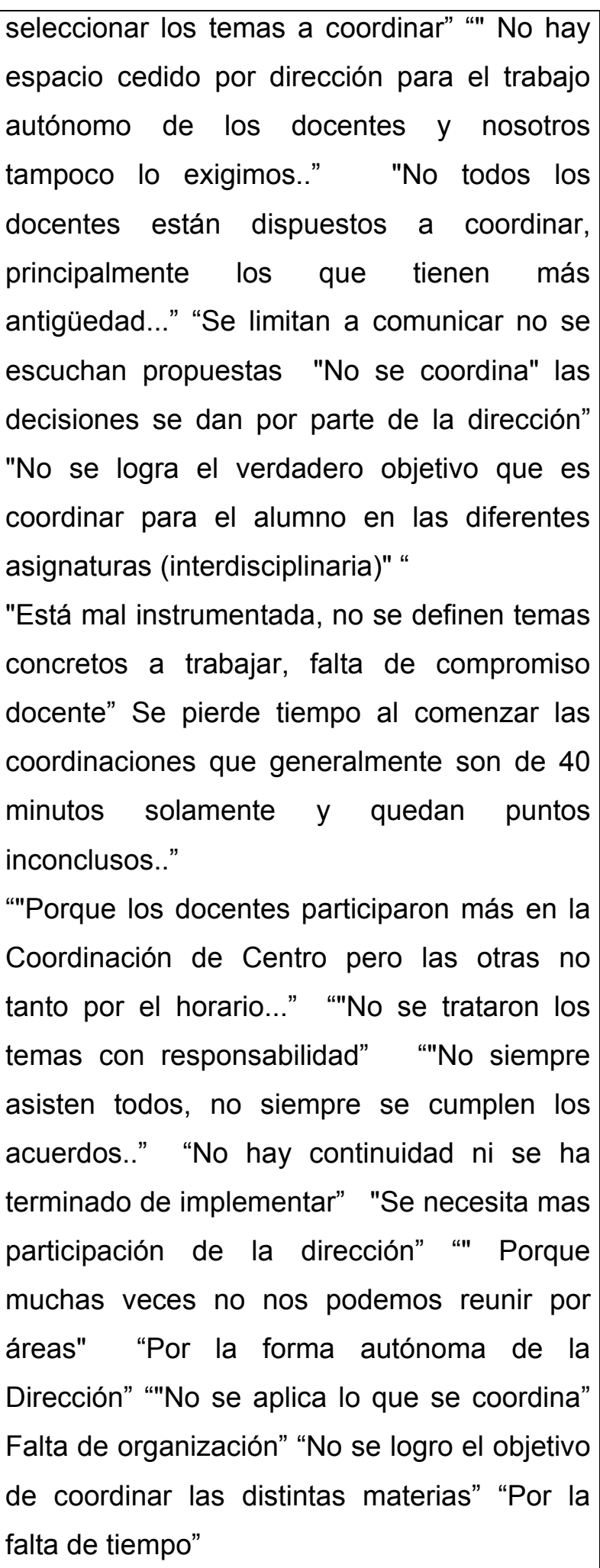 & $\begin{array}{l}\text { que comprometa al docente con la realidad" "Es } \\
\text { una pérdida de tiempo no incide en la práctica } \\
\text { educativa" "Porque no se coordina. Son } \\
\text { monólogos de los directores" Se utiliza para } \\
\text { desmotivar a los docentes y exigirles mejores } \\
\text { rendimientos del alumnado" "Nunca se tiene en } \\
\text { cuenta la opinión docente, predomina un } \\
\text { liderazgo negativo y no fomenta la cultura } \\
\text { colaborativa, además de ser totalmente } \\
\text { inflexible" } \\
\text { "Porque ha estado lejos de ser una coordinación } \\
\text { se parece más a una charla entre amigos..." No } \\
\text { son bien preparadas por quien la guía y siempre } \\
\text { terminan en una mera discusión sobre cosas } \\
\text { que al final no se acuerda en nada" " "no se } \\
\text { respeta en varias instancias la importancia de la } \\
\text { opinión docente como protagonista de las } \\
\text { actividades del centro y en el aula" "“Falta de } \\
\text { autonomía de los docentes y espacio de } \\
\text { producción docente y de reflexión" } \\
\text { "'Los temas tratados no se adaptan a las } \\
\text { necesidades del centro." "Porque generalmente } \\
\text { los temas suelen desviarse hacia } \\
\text { tratados no motivan a los docentes a participar. } \\
\text { Se asiste por obligación (evitar el descuento). } \\
\text { tratado temas urgentes, conducta, deserción,." }\end{array}$ \\
\hline
\end{tabular}


El análisis de las representaciones del profesorado principiante, nos permite conocer cómo es percibido y evaluado el espacio de coordinación. Podemos resumir la información cualitativa registrada, respondiendo a la siguiente pregunta: ¿Cuáles son las condiciones que determinan un buen funcionamiento de la coordinación docente?

Según la opinión del profesorado, las principales características de una coordinación "que funciona", serían las siguientes:

- Claridad de los objetivos por parte de la Dirección - Participación docente en la definición de los temas (planificación, proyectos de aula, talleres, etc) Compromiso docente y disposición al trabajo colaborativo - Pautas claras para implementar la coordinación por parte de la Dirección - Autonomía de los profesores - Asistencia de los docentes, responsabilidad - Coordinación por áreas - Organización del tiempo y del horario acorde con los objetivos Trabajar en equipo, reflexión colectiva del profesorado

- Clima de trabajo positivo - Lograr resultados y evaluar las estrategias aplicadas

- Organización de actividades que efectivamente benefician al alumnado y al centro.

Por otra parte, identificamos una serie de características asociadas al mal funcionamiento de la coordinación, algunas de ellas atribuibles al perfil del director de cada institución y otras a la falta de compromiso de un sector del profesorado (que podría ser, como hipótesis, consecuencia de la primera).

Del análisis de todas las respuestas abiertas que se registraron como juicios negativos hacia la coordinación, destacamos la siguiente lista de temas o emergentes planteados por los profesores:

- Escasa valoración de la autonomía del profesorado - No existen propuestas de interés que comprometan al docente - La presión de las autoridades para lograr determinados objetivos - Falta un liderazgo claro del equipo de dirección - No hay espacios para la reflexión colegiada - Falta comunicación, diálogo efectivo entre la Dirección y los profesores - No hay pautas ni estructuras claras para la coordinación de actividades

- Falta la coordinación interdisciplinaria por áreas - Los profesores no se comprometen con la coordinación - No se cumplen los acuerdos 
Parece claro, de acuerdo con la información analizada hasta aquí, que los resultados del trabajo en coordinación no pueden ser demasiado alentadores, debido a la fuerte división del profesorado sobre el sentido de esta innovación. Las nuevas prácticas de participar democráticamente en la gestión de los centros, deben enfrentar diferentes obstáculos, algunos de ellos de la propia administración, otros relativos al liderazgo institucional y a la presión que muchos directores hacen para lograr determinados objetivos educativos.

Muchos docentes manifiestan desamparo y desorientación, porque son convocados a participar en reuniones donde los temas ya están previamente seleccionados, asuntos que en muchos casos no reflejan el verdadero interés del profesorado. Si bien hay instituciones "modelos" donde los profesores están altamente comprometidos, especialmente en los departamentos de Río Negro, Artigas y Paysandú, es posible percibir cierto malestar generalizado sobre los escasos resultados de las horas de coordinación docente, porque las metas de "“planificar, desarrollar el curriculum y las propuestas pedagógicas con sus pares y el equipo de dirección" tal como lo expresan las disposiciones reglamentarias vigentes, no se cumplen por diferentes razones.

\subsubsection{La participación docente en el Proyecto de Centro}

Una lectura comparada de los últimos planes de educación media en nuestro país (19631986, ajuste del período 1991-1995 y los nuevos programas de la reforma iniciada en el año 1996) es un ejercicio útil para identificar propuestas innovadores que se mantienen, con los arreglos de cada nueva administración, a través del tiempo. Por ejemplo, el plan de 1963 ya esbozaba como objetivo general posibilitar la integración del alumno a la comunidad, lo que podría ser el primer antecedente de incorporar en los centros de educación media la idea de acercar los establecimientos al entorno social. El diseño curricular por áreas, es otro ejemplo de innovación que no es exclusivo del plan 1996. Ya en el año 1986, las autoridades definían una nueva organización del conocimiento estructurado en cuatro áreas: expresión, ciencias experimentales y tecnología, ciencias sociales y las actividades planificadas optativas. La introducción de talleres y la recomendación metodológica de que los docentes abandonen la influencia universitaria del "catedrático" para ser "maestro" de educación media, ya se trazaba en el programa de 1963.

El uso de la metodología "activa" de la enseñanza, impulsando la participación de los alumnos, es uno de los propósitos principales que aparece en todos los diseños curriculares mencionados. Otros ejemplos podrían aludirse, para demostrar la dinámica de los cambios 
curriculares, que van y vienen, con distinta intensidad y prioridad por los diferentes programas. Pero hay una innovación que aparece como original de la reforma del año 1996. Nos referimos a la nueva concepción de centro educativo, donde "los actores asuman capacidad de iniciativa y de innovación, orientados por la elaboración y puesta en marcha de un Proyecto Educativo que los identifique y los organice a partir de la formulación de objetivos educativos y pedagógicos comunes" (ANEP, 1996, Doc. II, p.15).

En este apartado nos interesa conocer en qué medida los profesores principiantes han participado en la formulación de los proyectos educativos de centro (PEC), ya que éstos representan, según la propia administración "uno de los avances más significativos alcanzados por los centros piloto a lo largo de los dos primeros años de puesta en práctica del nuevo modelo (1996-1997)", y la experiencia indica que "se trabaja intensamente en la elaboración e implementación de un Proyecto a nivel del centro educativo, que aglutina y compromete a directores, docentes y estudiantes, confiriéndole un sentido y una dirección a la gestión, estableciendo prioridades, seleccionado estrategias y evaluando procesos y logros" (ANEP, 2000, p. 214).

Además averiguamos el grado de involucramiento de los educadores en la elaboración del PEC y si éste refleja realmente el punto de vista del profesorado. Aunque parece obvio que las iniciativas en el trabajo institucional colegiado correspondan a los profesores más experimentados, no debemos olvidar que los nuevos docentes egresados de los CERP recibieron una formación apropiada para el trabajo en proyectos. Además, las autoridades de la enseñanza ha promovido de forma reiterada, distintas instancias de capacitación de profesores y directores en la nueva gestión institucional de los establecimientos de educación media. ¿Existe un Proyecto Educativo en cada centro o varios microproyectos coordinados por un objetivo común? ¿Hay relación entre la formulación teórica del proyecto y las prácticas de los educadores, tal como lo prevén las nuevas orientaciones metodológicas?

En este sentido, aceptamos la hipótesis formulada por Alsinet en un artículo publicado en Cuadernos de Pedagogía (1995, p. 1) quien afirma que la existencia de un Proyecto de Centro totalizador es "un sueño de la razón burocrática", trazando la distinción, para el análisis, entre el "proyecto-documento" y el "proyecto acción". Desde nuestro punto de vista, las instituciones con mayor autonomía real de los agentes educativos e independencia de las autoridades centrales podrán construir uno o varios proyectos de acción, innovando sus 
prácticas para evaluar acciones, logros y resultados. Por el contrario, los centros con mayor dependencia jerárquica de las autoridades centrales e intermedias, tendrán como prioridad el objetivo de plasmar en papeles las ideas del proyecto-documento, priorizando la redacción formal de un informe que muchas veces ni siquiera es leído o simplemente no implica ningún compromiso para los participantes.

\subsubsection{Participación de los profesores principiantes en el PEC}

Las tareas de campo de la investigación fueron efectuadas en los últimos meses del año escolar 2004, por lo cuál es razonable suponer que en la mayoría de los centros educativos donde trabajan los profesores principiantes consultados, ya tenían elaborado el Proyecto de Centro. Normalmente en nuestro país, los primeros días del año son destinados para efectuar diagnósticos de aula e institucionales, posteriormente las respectivas direcciones escolares convocan a los docentes a participar de las reuniones de coordinación, donde la preparación del Proyecto de Centro es la tarea principal. Recordemos que según la metodología definida previamente, relevamos información de 24 centros educativos de la región litoral del Uruguay ubicados en 5 departamentos $^{5}$ (8 instituciones de Salto, 5 de Artigas, 8 de Paysandú y 3 de Río Negro) por lo que las conclusiones deben comprenderse con un carácter aproximativo y exploratorio. De todas maneras, los resultados representan una primera contribución a un tema escasamente evaluado por las autoridades y los técnicos que monitorean los cambios del sistema educativo.

Es interesante conocer, antes de seguir, el clima institucional percibido por los profesores en cada institución. Una forma indirecta de medir este fenómeno, es preguntarse por el grado de comunicación entre los docentes, y entre éstos con la dirección del centro. Una hipótesis muy básica nos dice que no puede surgir un proyecto de elaboración colectiva si no hay ciertas condiciones mínimas, como por ejemplo, canales de comunicación y diálogo fluido entre los actores que pauten un clima de convivencia propicio para emprender acciones colectivas que requieren de negociaciones, consensos y acuerdos entre los distintos intereses.

\footnotetext{
${ }^{5}$ Uruguay se divide políticamente en 19 jurisdicciones denominados departamentos. El estudio abarca los departamentos de Salto, Artigas, Paysandú y Río Negro, ubicados en el litoral norte, entre las fronteras de Argentina y Brasil.
} 


\section{Tabla No 10}

La comunicación en los centros

\begin{tabular}{|c|c|c|c|c|c|c|c|c|}
\hline & \multicolumn{2}{|c|}{$\begin{array}{l}\text { Cómo es la } \\
\text { comunicación } \\
\text { entre profesores } \\
\text { interinos y } \\
\text { efectivos? }\end{array}$} & \multicolumn{2}{|c|}{$\begin{array}{c}\text { Cómo es } \\
\text { lacomunicación } \\
\text { entre los } \\
\text { profesores } \\
\text { principiantes y } \\
\text { los } \\
\text { experimentados? }\end{array}$} & \multicolumn{2}{|c|}{$\begin{array}{c}\text { Cómo es la } \\
\text { comunicación } \\
\text { de los profesores } \\
\text { del CERP con } \\
\text { los colegas? }\end{array}$} & \multicolumn{2}{|c|}{$\begin{array}{c}\text { ¿Cómo es la } \\
\text { comunicación } \\
\text { entre los } \\
\text { docentes y la } \\
\text { Dirección? }\end{array}$} \\
\hline & $\mathrm{N}$ & $\%$ & $\mathrm{~N}$ & $\%$ & $\mathrm{~N}$ & $\%$ & $\mathrm{~N}$ & $\%$ \\
\hline muy buena & 133 & 47,8 & 91 & 33,0 & 91 & 34,2 & 90 & 32,6 \\
\hline buena & 113 & 40,6 & 132 & 47,8 & 117 & 44,0 & 109 & 39,5 \\
\hline regular & 29 & 10,4 & 46 & 16,7 & 49 & 18,4 & 61 & 22,1 \\
\hline mala & 3 & 1,1 & 7 & 2,5 & 9 & 3,4 & 16 & 5,8 \\
\hline Total & 278 & 100,0 & 276 & 100,0 & 266 & 100,0 & 276 & 100,0 \\
\hline
\end{tabular}

Elaboración propia

Los resultados que se exhiben en la Tabla $\mathrm{N}^{\circ} 10$ representan los porcentajes de respuestas que miden cómo los profesores principiantes valoran la comunicación entre diferentes tipos de estamentos profesionales presentados como pares dicotómicos. En términos generales predomina la apreciación de que la comunicación es buena o muy buena entre los diferentes actores, aunque existen algunos indicios de que en ciertos liceos el vínculo de los docentes con la dirección no es el mejor. Por ejemplo, del total de profesores que respondieron a esta pregunta para el caso de la comunicación entre docentes y la dirección del centro, el 27,9 \% manifiesta que la misma es regular o mala, lo que reflejaría una situación de tensión que no favorece la construcción de proyectos compartidos.

Aproximadamente uno de cada cinco docentes $(20 \%)$ entiende que la comunicación no es buena con los profesores experimentados, ni entre los profesores egresados del CERP con sus colegas. Coordinar con los efectivos no parece ser un problema para los profesores principiantes.

\section{Tabla No 11}

Elaboración del PEC

\begin{tabular}{|c|c|c|c|c|}
\hline \multirow{3}{*}{$\begin{array}{l}\text { En este LICEO o ESCUELA } \\
\text { TÉCNICA en que medida } \\
\text { tienen elabroado el Proyecto } \\
\text { Educativo de Centro? }\end{array}$} & \multicolumn{4}{|c|}{$\begin{array}{c}\text { SUBSISTEMA DONDE } \\
\text { TRABAJA } \\
\end{array}$} \\
\hline & \multicolumn{2}{|c|}{ Secundaria } & \multicolumn{2}{|c|}{$\begin{array}{c}\text { Educación } \\
\text { Técnica (UTU) }\end{array}$} \\
\hline & $\mathrm{N}$ & $\%$ & $\mathrm{~N}$ & $\%$ \\
\hline No hemos comenzado & 22 & 14,0 & 19 & 16,8 \\
\hline Estamos discutiendo & 29 & 18,5 & 19 & 16,8 \\
\hline Lo tenemos elaborado & 50 & 31,8 & 45 & 39,8 \\
\hline $\begin{array}{l}\text { Lo tenemos completamente } \\
\text { elaborado }\end{array}$ & 56 & 35,7 & 30 & 26,5 \\
\hline Total & 157 & 100,0 & 113 & 100,0 \\
\hline
\end{tabular}


También indagamos si efectivamente el PEC es un producto acabado o en proceso. Dado la fecha de realizada la investigación, era razonable suponer que todos los centros habían culminado de confeccionar sus proyectos.

Sin embargo, tal como lo refleja la Tabla № 11 , todavía una de cada tres de las instituciones consultadas no habían culminado la tarea. Llama la atención que el 16,8 \% de las instituciones de la enseñanza técnica ni el $14 \%$ de los liceos de secundaria, ni siquiera lo habían comenzado, según la percepción del profesorado consultado. Es una situación difícil de comprender ya que, como hemos dicho en párrafos anteriores, la elaboración del PEC es obligatoria, tanto para las autoridades que supervisan el centro (Inspectores y Directores) como para los docentes cuyo contrato laboral incluye una remuneración específica para esa labor.

Una hipótesis posible es que el proyecto-documento existe pero no es conocido por los docentes porque no fue debatido por la comunidad educativa. La forma de contrastar estas ideas es consultar a los educadores sobre su participación en la elaboración del PEC. Según los antecedentes que se presentan en la Tabla $N^{0} 11$ los profesores principiantes tienen un escaso protagonismo en la redacción del proyecto. No han participado el $37 \%$ de los profesores que tienen mayor carga horaria en secundaria, y el $61,2 \%$ de sus colegas que trabajan más horas en la educación técnica. ¿Esto es así porque quienes lideran la formulación y puesta en práctica del proyecto son los docentes más experimentados? ¿o la baja participación es una característica general de un estilo de gestión democrática que todavía no ha logrado desarrollarse?

Es necesario que nuevas investigaciones ahonden en esta problemática, para seguir estudiando el proceso de las transformaciones en marcha. De todas maneras, es sorprendente el escaso compromiso del profesorado joven en la formulación del PEC: sólo un $17,6 \%$ participó activamente en secundaria, y apenas el $6 \%$ en la educación técnica. Solamente 4 casos, en un total de 271 profesores que respondieron esta preguntaron, se identificaron con la frase "me siento responsable del proyecto". El problema tiene mayor gravedad en las instituciones de educación técnica, donde la participación es más baja aún. Ante este fenómeno, es pertinente preguntarse si el PEC refleja realmente el punto de vista del profesorado. 


\section{Tabla No 12}

Participación de los docentes en la elaboración del PEC

\begin{tabular}{|c|c|c|c|c|}
\hline \multirow{3}{*}{$\begin{array}{l}\text { ¿Cómo ha participado } \\
\text { Ud. en la elaboración } \\
\text { del PEC? }\end{array}$} & \multicolumn{4}{|c|}{$\begin{array}{c}\text { SUBSISTEMA DONDE } \\
\text { TRABAJA }\end{array}$} \\
\hline & \multicolumn{2}{|c|}{ Secundaria } & \multicolumn{2}{|c|}{$\begin{array}{c}\text { Educación } \\
\text { Técnica } \\
\text { (UTU) } \\
\end{array}$} \\
\hline & $\mathrm{N}$ & $\%$ & $\mathrm{~N}$ & $\%$ \\
\hline No he participado & 58 & 37,4 & 71 & 61,2 \\
\hline He participado poco & 67 & 43,2 & 37 & 31,9 \\
\hline He participado activamente & 27 & 17,4 & 7 & 6,0 \\
\hline $\begin{array}{l}\text { Me siento responsable del } \\
\text { proyecto }\end{array}$ & 3 & 1,9 & 1 & ,9 \\
\hline Total & 155 & 100,0 & 116 & 100,0 \\
\hline
\end{tabular}

Interrogamos a los profesores sobre este asunto, para tener más elementos interpretativos. Si examinamos los datos de la Tabla $\mathrm{N}^{\circ} 13$, es posible apreciar que el $41,1 \%$ del profesorado de secundaria y el $34,5 \%$ de aquellos que se desempeñan en la enseñanza técnica, están de acuerdo en que los objetivos del PEC reflejan los intereses del profesorado.

\section{Tabla No 13}

¿EI PEC refleja realmente el punto de vista del profesorado?

\begin{tabular}{|l|c|c|c|c|}
\hline \multirow{2}{*}{\begin{tabular}{l} 
Usted considera, en térmi \\
\cline { 2 - 5 } generales que el PEC refl
\end{tabular}} & \multicolumn{4}{|c|}{ SUBSISTEMA DONDE } \\
TRABAJA \\
\cline { 2 - 5 } realmente el punto de vist \\
\cline { 2 - 5 } profesorado? & $\mathrm{N}$ & $\%$ & $\mathrm{~N}$ & \multicolumn{2}{c|}{$\begin{array}{c}\text { Educación } \\
\text { Técnica (UTU) }\end{array}$} \\
\hline Totalmente de acuerdo & 13 & 8,0 & 10 & 8,8 \\
De acuerdo & 54 & 33,1 & 29 & 25,7 \\
Neutral & 50 & 30,7 & 34 & 30,1 \\
En desacuerdo & 9 & 5,5 & 16 & 14,2 \\
Totalmente en desacuerdo & 5 & 3,1 & 7 & 6,2 \\
No lo sabe & 32 & 19,6 & 17 & 15,0 \\
Total & 163 & 100,0 & 113 & 100,0 \\
\hline
\end{tabular}

Elabroación propia 
Los antecedentes son elocuentes al poner de relieve que uno de cada tres profesores no tiene opinión al respecto, es "neutral". Además, el 19,6 \% de los docentes de secundaria y el $15 \%$ de la enseñanza técnica, contesta que "no lo sabe" lo que indica claramente un desconocimiento de los objetivos del PEC. De la misma manera, uno de cada cinco profesores principiantes $(20,4 \%)$ que se desempeñan en la educación técnica manifiesta su desacuerdo con la afirmación, siendo algo menor este porcentaje entre los profesores de secundaria (8,6\%). En síntesis, la información estadística contrastada deja en evidencia la baja participación del profesorado joven en la elaboración del PEC, la existencia de problemas en la comunicación con la dirección en cada centro y la puesta en duda de que las metas del PEC signifiquen acuerdos logrados por la comunidad educativa.

Es probable que en muchos casos los proyectos de centro expresen los intereses de las autoridades, porque es escasa la comunicación interna institucional que propicia la interacción entre profesores y porque los mismos participantes tienen dudas sobre los objetivos del PEC, que en algunos centros no representan sus intereses ni las inquietudes del profesorado.

No cabe duda de que lo está en juego aquí es la presencia o no de un escenario democrático qué, respetando la autonomía del profesorado, beneficie la integración real y creativa de todos los agentes educativos. En efecto, podemos concluir que en los establecimientos estudiados, es muy limitada la implicación del profesorado en la redacción, puesta en marcha y evaluación de los proyectos educativos de centro. ¿Esto es atribuible a la inexperiencia de los profesores novatos? ¿o a un estilo de organización institucional determinado que piensa las instituciones como espacios de poder jerarquizado piramidalmente según los conceptos clásicos de la gestión tradicional?

La información estadística de la Tabla № 14 nos revela que el problema es más grave según la percepción del profesorado egresado del CERP y de los docentes universitarios o sin especialización pedagógica. En estos casos, sólo el 34\% y el 38,4\% respectivamente, dice estar de acuerdo o totalmente de acuerdo en que las metas del PEC encarnan efectivamente los intereses de los profesores, mientras que el resto pone en duda esa afirmación. 


\section{Tabla No 14}

REspuestas a la pregunta: ¿el PEC refleja el punto de vista del profesorado? según la formación docente de los encuestados.

\begin{tabular}{|c|c|c|c|c|c|c|}
\hline \multirow{3}{*}{$\begin{array}{l}\text { Usted considera, en términos } \\
\text { generales que el PEC refleja } \\
\text { realmente el punto de vista } \\
\text { del profesorado? }\end{array}$} & \multicolumn{6}{|c|}{ Formación docente de los profesores encuestados } \\
\hline & \multicolumn{2}{|c|}{$\begin{array}{l}\text { Titulado } \\
\text { "CERP" }\end{array}$} & \multicolumn{2}{|c|}{$\begin{array}{c}\text { Titulado } \\
\text { "IFD-IPA-MA } \\
\text { G" }\end{array}$} & \multicolumn{2}{|c|}{$\begin{array}{c}\text { Egresados } \\
\text { Universitarios y } \\
\text { estudiantes }\end{array}$} \\
\hline & $\mathrm{N}$ & $\%$ & $\mathrm{~N}$ & $\%$ & $\mathrm{~N}$ & $\%$ \\
\hline Totalmente de acuerdo & 8 & 6,5 & 5 & 16,1 & 10 & 8,5 \\
\hline De acuerdo & 35 & 28,5 & 12 & 38,7 & 35 & 29,9 \\
\hline Neutral & 44 & 35,8 & 6 & 19,4 & 31 & 26,5 \\
\hline En desacuerdo & 13 & 10,6 & 2 & 6,5 & 10 & 8,5 \\
\hline Totalmente en desacuerdo & 9 & 7,3 & 1 & 3,2 & 1 & ,9 \\
\hline No lo sabe & 14 & 11,4 & 5 & 16,1 & 30 & 25,6 \\
\hline Total & 123 & 100,0 & 31 & 100,0 & 117 & 100,0 \\
\hline
\end{tabular}

Es significativo que los profesores egresados de los Centros Regionales, quienes reciben una preparación intensiva -en su formación inicial- para la formulación de proyectos educativos, igualmente expresen su disconformidad sobre este tema, siendo este grupo el que se pronuncia categóricamente en desacuerdo con esta afirmación (el 17,9 \% afirma que el PEC no representa el punto de vista de los profesores) y el 35,8 \% asume una posición neutral.

\section{Reflexiones finales}

En este artículo hemos examinado las valoraciones de los profesores principiantes que recién ingresan a la docencia en la educación media, sobre dos de los componentes principales, -aunque no exclusivos- de la reforma curricular de 1997 en Uruguay: la coordinación docente y el trabajo en proyectos de centro.

Según la nueva concepción del centro educativo, la misión de los establecimientos debe jerarquizar la construcción de espacios de coordinación, -para intercambiar experiencias y visiones sobre el trabajo pedagógico colaborativo- y lograr acuerdos sobre los proyectos de aula para mejorar las condiciones del aprendizaje. Este modelo de gestión es estimulado a partir de las nuevas disposiciones organizativas de los establecimientos que disponen la elaboración, con carácter obligatorio, de un proyecto de centro que comprometa a la 
dirección, los docentes, el alumnado, los padres y el resto de organizaciones de la comunidad a coordinar estrategias para mejorar el proceso de enseñanza.

Uno de los objetivos principales es que los docentes abandonen el rol tradicional de "profesor de asignatura" para ejercer un nuevo papel como integrantes del colectivo docente, trabajando en equipo, participando democráticamente en la toma de decisiones responsables con la finalidad de mejorar la calidad de la enseñanza y de los aprendizajes. Para llevar a cabo esas metas, los docentes disponen de horas de coordinación donde intercambian enfoques con sus colegas sobre la implementación de los nuevos programas, investigan las condiciones de aprendizaje de sus alumnos y elaboran un proyecto colectivo propio de cada centro educativo.

El análisis de la información cualitativa y cuantitativa relevada pone de manifiesto el fuerte peso que tienen ciertas prácticas institucionales objetivadas, -en el sentido que le da Bordieu al término- como el rol tradicional de los directores y la estructura del puesto de trabajo de los docentes. La cultura institucional objetivada, mediante las prácticas burocráticas tradicionales como la lectura de informes administrativos, reglamentaciones y ordenanzas, oficia como obstáculo para los intentos de introducir nuevos proyectos innovadores. Es decir, el peso de ciertas rutinas burocráticas es de tal magnitud, que los deseos de cambiar se chocan contra una realidad institucional fuertemente marcada por la reproducción inercial de los viejos esquemas organizadores de la enseñanza. Sólo así puede entenderse que una política de gestión de los establecimientos que se basa en la construcción de nuevos espacios para la coordinación de todos los agentes educativos, deba enfrentar el problema de que muchos profesores no pueden participar de las reuniones de coordinación, porque los horarios, definidos por las propias autoridades, no lo permiten.

Otro asunto que merece atención, es el de la autonomía del profesorado, mencionado como una condición indispensable para el logro de proyectos de centro "con sentido" para los participantes. Las reuniones de coordinación, según la visión del profesorado que recién ingresa a la docencia, están reglamentadas y definidas por los directores en la mayoría de los casos, siendo el enfoque preferido el de tratar la "problemática del alumno" como tema central, en especial lo relativo a la deserción, rezago, niveles de aprendizaje y en menor medida el control de la disciplina. 
El malestar de muchos profesores principiantes, la mitad de la muestra seleccionada, es un indicador elocuente de las dificultades existentes para trabajar en equipo con una cultura de colaboración. Algunos de los factores señalados, como la coacción de las autoridades para lograr determinados objetivos y no otros (generalmente vinculados a la presión hacia los docentes en los momentos de la evaluación asegurando el pasaje de grado universal) o la falta de pautas y estructuras claras para la coordinación de actividades tienen que ver con el perfil pedagógico y el estilo de gestión tradicional preferido por los responsables en cada establecimiento.

Otras razones expuestas en el análisis dejan en evidencia las dificultades que tienen los docentes principiantes para participar en programas de intervención, proyectos de aula o de investigación educativa, porque los temas sugeridos no se adecuan a sus intereses, no tienen espacios para expresar sus opiniones y en muchos casos, la presión institucional prioriza la coordinación general antes que la coordinación interdisciplinaria por área de conocimiento. La meta de "lograr resultados y evaluar las estrategias empleadas" propósitos claramente definidos por las nuevas teorías de la planificación estratégica, debe ser planteada de tal manera que implique un abanico amplio de posibilidades.

Sin embargo, la coerción que ejercen muchos directores para definir "que temas" se discuten, y "cómo" deben organizarse los centros para alcanzar objetivos de política educativa fácilmente medibles con indicadores "duros" (como la tasa de pasaje de grado o la deserción) puede constituirse en un obstáculo para la mejora de la enseñanza porque desconoce la complejidad del universo social y político de la educación. Es un error, confundir, como bien lo ha aclarado S. Ball (1994, p. 55), que los cambios de política impliquen mecánicamente una modificación de las prácticas educativas, ni que exista correspondencia entre el ámbito público del debate -como lo es la coordinación de centro-, con el ámbito privado de la práctica. Las declaraciones de los profesores principiantes (del tipo: "todo lo que diga el docente podrá ser usado en su contra ", "los docentes son culpables del fracaso de sus alumnos" "en las reuniones de coordinación se pierde el tiempo" "se culpa al docente de no tener la libreta al día" y otras del mismo tenor) ponen de relieve, además, las diferencias entre la participación real en la toma de decisiones, la pseudoparticipación y el control burocrático de la función docente. Siguiendo los aportes de Sacristán (1998, p. 326) parecería que en las instancias de coordinación se confunde lo público (ámbito abierto para el debate democrático) con lo estatal (espacio donde el Estado 
tiene poder absoluto) cuando en realidad son esferas independientes. Esta distinción es necesaria para comprender cabalmente hasta donde hablamos de democracia real o participación artificial.

El discurso predominantemente técnico de la reforma, no sólo en Uruguay, -sino en la mayoría de los países occidentales- desacomoda y desorienta a los profesores que reclaman una participación efectiva en la discusión pública sobre los objetivos de los proyectos institucionales, los intereses que representan así como los valores educativos que se defienden. La retórica de la profesionalidad docente, tal como lo resalta Pérez Gomar, (2001) choca con la realidad del profesorado, que tiene más autonomía virtual pero menos poder real para decidir sobre las prácticas que regulan su puesto de trabajo.

El escenario de las reuniones de coordinación, es un espacio donde disputan sus intereses los grupos subalternos con los que tienen posiciones de poder, en el cual las discusiones son iniciadas y controladas por el director. En la mayoría de las escuelas estatales, comenta S. Ball (1994, p.235)

(..) la reunión de personal típicamente es una oportunidad para repetir y confirmar la definición oficial de la escuela" por eso "los profesores pasan a condición de público. No son tanto participantes como espectadores de la reunión. La reunión es un camuflaje, una diversión. El ritual de dar información y consultar predomina sobre toda participación sustancial en la toma de decisiones. La conversación, en estas circunstancias versa sobre el control y "sobre la autoridad.

El examen de los juicios y las representaciones del profesorado principiante, es concluyente al establecer, además, que los proyectos verdaderamente institucionales, con una fuerte participación social de la comunidad no son temas prioritarios para las autoridades de las instituciones de educación media analizadas.

Este panorama coloca a los docentes en una doble lógica, tal como la llama Contreras (1998, p. 192) ya que la retórica oficial promueve la autonomía de los centros, pero ésta es fuertemente controlada por los niveles intermedios del sistema (Inspectores y Directores) de la misma manera que el discurso de la reforma le otorga más responsabilidad a los docentes pero simultáneamente éstos son más controlados y regulados por disposiciones 
administrativas. Por eso es necesario advertir, antes de terminar, que la autonomía del profesorado debe contemplar el escenario político, intelectual y pedagógico. No sólo los aspectos de gestión o de regulación administrativa.

El éxito de las nuevas políticas educativas que defienden una mayor descentralización y autogestión de los centros, estará condicionado por la coherencia entre el discurso y los estilos de gestión de los cambios, otorgándole al profesorado no sólo más responsabilidades sino nuevos espacios de poder real para que los docentes puedan efectivamente transformar sus prácticas. Este proceso no es fácil, avanza con las turbulencias propias de las transformaciones educativas que se estremecen entre el mundo de los dispositivos teóricos y los escenarios concretos de las instituciones escolares. Escenarios donde se oponen viejas y nuevas culturas profesionales.

Necesitamos entender estos cambios, -que no son procesos lineales ni causales-, como algo más complejo que la planificación racional orientada por fines ideológicos que no comprenden la naturaleza burocrática de las organizaciones ni los espacios de poder que reclaman, con justicia, los profesores. El éxito o el fracaso de las innovaciones, dependerá, entre otros factores, del protagonismo docente en el diseño y en la puesta en práctica de las nuevas transformaciones institucionales necesarias para mejorar la calidad de la educación secundaria.

\section{REFERENCIAS BIBLIOGRAFICAS}

Alsinet, J; Muñoz, E. (1995). Proyecto De Centro: un universo de posibilidades. Revista Cuadernos de Pedagogía. (238):1-3.

ANEP/MEMFOD. (2003). Estudio del impacto de la formación de los egresados de los Centros Regionales de Profesores (CERP) en la primera etapa de su ciclo profesional. Montevideo: ANEP.

ANEP-CODICEN. (1996). La Reforma de la Educación. Los Planes de estudio y el cambio educativo. Seguimiento de la Experiencia Piloto del Ciclo Básico. Documentos III-IV. Montevideo: ANEP.

ANEP. (2000). Una visión integral del proceso de reforma educativa en Uruguay 19951999. Montevideo: ANEP.

Avalos, B. (1999). Mejorando la formación de profesores. El programa de fortalecimiento de la formación inicial docente en Chile. Conferencia presentada en Congreso "Los maestros en América Latina: Nuevas perspectivas sobre su Desarrollo y Desempeño. San José de Costa Rica. 
Ball, S. (1994). La Micropolítica de la Escuela. Hacia una teoría de la organización escolar. Barcelona. Piados.

Bolívar, A. (1999). Ciclo de Vida Profesional del Profesorado de Secundaria. Bilbao: Mensajero.

Braslasky, C. La Educación Secundaria en el contexto de los cambios en los sistemas educativos latinoamericanos. Revista Iberoamericana de Educación $\mathrm{N}^{\circ} 9$. Biblioteca Digital de la OEI. Recuperado el 18 de agosto de 2004, de http://www.campusoei.org/oeivirt/rie09a03.htm

CEPAL. (1999). Panorama social de América Latina. Santiago de Chile. Naciones Unidas: CEPAL.

CEPAL. (1998). Panorama social de América Latina. Santiago de Chile. Naciones Unidas: CEPAL.

Contreras, D. (1991). El sentido educativo de la investigación. Cuadernos de Pedagogía, (196), 3-4.

Contreras, D. (1998). La Autonomía del Profesorado. Madrid: Morata.

Cornejo, J. (1999). Profesores que se inician en la docencia: algunas reflexiones al respecto desde América Latina. Revista Iberoamericana de Educación № 19 , enero-abril de 1999. OEl. Recuperado el 17 de noviembre de 2004, de http://www.campusoei.org/oeivirt/rie19a02.htm

Cox, S.; Heames, R. (2000). Cómo enfrentar el malestar docente. Estrategias e ideas prácticas para los tutores y sus alumnos. Barcelona-Buenos Aires-México: Octaedro.

Davini, M.C. Coord. (2002). De aprendices a maestros. Enseñar y aprender a enseñar. Buenos Aires: Papers Editores.

De Mello, G. (2002). Formación de Profesores en América Latina y el Caribe. A la búsqueda de la innovación y la eficiencia. Conferencia Internacional sobre el desempeño de los profesores en América Latina. Tiempo de nuevas prioridades. Brasilia: (mimeo).

Esteve, J.M. (1993). El choque de los principiantes con la realidad. Cuadernos de Pedagogía (220), 3-4.

Esteve, J.M. (1997). La Formación Inicial de los Profesores de Secundaria. Barcelona. Ed. Ariel.

Esteve, J.M. (1987). El malestar docente. Madrid: Paidos.

Esteve, J.M. (1984). Profesores en Conflicto. Repercusiones de la práctica profesional sobre la personalidad de los enseñantes. Madrid: Narcea. 
Gajardo, M. (1999). Reformas Educativas en América Latina: Balance de una década. Documentos del PREAL № 15. Santiago: PREAL.

Gimeno Sacristán, J. (1998). Poderes inestables en educación. Madrid: Morata.

Imbernón, F. (1994). La formación del Profesorado. Barcelona: Paidos.

Mancebo, E. y Vaillant, D. (2002) Principales aspectos de la situación de los formadores jóvenes en el Uruguay. La transformación en la formación docente. Revista Educar. ANEP-CODICEN. Año 4. (10): 3-9.

Marchesi, A. (2001). Cambios sociales y cambios educativos en Latinoamérica. PROMEDLAC VII. Santiago: UNESCO.

Pérez Gomar, G. (2001) Reforma e innovación educativa. Revista Relaciones. Serie REducación XVII. Montevideo. pp. 13-19 (documento en línea) Recuperado el 28 de marzo de 2005, de http://www.chasque.net/frontpage/relacion/9908/r educacion.htm;

Rodríguez Zidán, E. (2003). Los Profesores Debutantes en Educación Media: Una contribución al estudio de las innovaciones en el marco de la reforma educativa en Uruguay. Revista de Innovación Educativa. Universidad de Santiago de Compostela. España. (13): 369-395. Recuperado el 18 de noviembre de 2004, de www.usc.es/didoe/doc/revista/frames.htm

Tedesco, J.C.; López, N. (2002). Desafíos de la Enseñanza Secundaria en América Latina. Revista de la CEPAL. (76): 55-69.

Tedesco, J.C. (1996). El Nuevo Pacto Educativo. Educación, competitividad y ciudadanía en la sociedad moderna. Madrid: Anaya.

Tenti, E. (2002). Educación Media para todos. Unesco. IIPE. Buenos Aires: Altamira.

Tenti, E. (2000). Una Escuela para los adolescentes. Buenos Aires: UNICEF.

UNESCO. (2002). Docentes del Mañana: Análisis de los indicadores mundiales de educación. Ginebra: UNESCO.

UNESCO/OREALC. (1996). Proyecto Principal de Educación en América Latina y el Caribe. Boletín № 41. Santiago.

Vera, J. (1988). El profesor Principiante. Valencia: Promolibro.

Vera, J. (1989). El Profesor Principiante. Cuadernos de Pedagogía, (174), 3-7. 